\title{
Horizontes pedagógicos e pianísticos nas escritas autobiográficas de Magda Tagliaferro
}

\section{Resumo}

No presente artigo, aborda-se a trajetória pedagógica e musical de Magdalena Tagliaferro, artista que idealizou e implantou no Brasil, juntamente com Gustavo Capanema, o Curso Público de Interpretação Pianística. Com base no livro autobiográfico denominado Quase tudo, busca-se analisar a relevância da sua formação e os desdobramentos de seu trânsito entre o Brasil e a França, como também, as contribuições desta professora na consolidação da performance musical impressionista ao piano, estilo que influenciou muitos jovens brasileiros estudantes de música. Nesta perspectiva, percebe-se que, ao atravessar o Oceano Atlântico, a pianista estabelecia intercâmbios de conhecimentos didáticos, pedagógicos, musicais e técnicos interpretativos, promovendo a circularidade do saber entre os dois países.

Palavras-chave: Educação-História; Tagliaferro, Magdalena; Autobiografia; Viagens pedagógicas.

\section{Ednardo Monteiro Gonzaga Monti \\ Doutor em Educação pela Universidade do Estado do Rio de Janeiro - UERJ - Brasil ednardomonti@gmail.com}

\section{Para citar este artigo:}

MONTI, Ednardo Monteiro Gonzaga. Horizontes pedagógicos e pianísticos nas escritas autobiográficas de Magda Tagliaferro. Revista Linhas. Florianópolis, v. 16, n. 32, p. 150 - 171, set./dez. 2015. 


\section{Educational and pianistic horizons in the autobiographical writings of Magda Tagliaferro}

This article deals with the pedagogical and musical trajectory of Magdalena Tagliaferro, an artist who idealised and implemented, along with Gustavo Capanema, the Public Course of pianistic interpretation in Brazil. Based on the autobiographical book called Almost everything (Quase Tudo), I seek to analyse the relevance of their training and the ramifications of its transit between Brazil and France, as well as the contributions of this teacher towards the consolidation of impressionist musical performance on the piano, something which influenced many young Brazilian music students. In connection to this, it is clear that upon crossing the Atlantic Ocean, the pianist engaged in exchanges of didactic, pedagogical, musical and interpretive-technical knowledge, promoting the circularity of awareness between the two countries.

Keywords: Education-History; Tagliaferro, Magdalena; Autobiography; Pedagogical travel. 
Guardo minhas forças para a música e o amor. Magda Tagliaferro ${ }^{1}$

A epígrafe deste artigo é a frase que a professora de piano Magdalena Tagliaferro, em relato divulgado no documentário 0 mundo dentro de um piano (2004), falava quando se levantava da cadeira de rodas, no minuto que era abordada por admiradores, fãs e amigos nos aeroportos. Sempre estava com a sua peruca de cabelos ruivos. Na década de 1980, com mais de noventa anos, a concertista manteve-se transeunte pelos aeroportos do mundo afora e do Brasil adentro. Em sua longevidade, cruzar o Atlântico foi uma prática constante, seja para realizar turnês de recitais e concertos, para buscar novos conhecimentos pedagógicos, aprimoramento técnico-interpretativo, ou ainda, para transmiti-los em diferentes conservatórios no exterior e no Brasil por meio do Curso Público de Interpretação Pianística, que idealizou juntamente com Gustavo Capanema.

Instigado por essa frase, escrevo neste texto algumas reflexões sobre as viagens pedagógicas de Magdalena Tagliaferro. Isso a partir da deixa da sua fala emblemática nos aeroportos, que aborda os dois temas que fomentavam as suas viagens: a música e o amor. Aspectos que, quem sabe, podem tê-la permitido gozar a longevidade com a lucidez e com as energias necessárias para tocar piano até o final dos seus dias.

Dentre os seus escritos, para analisar as viagens da pianista, utilizo como principal fonte documental a autobiografia intitulada "Quase tudo... Memórias de Magdalena Tagliaferro", traduzida por Maria Lúcia Pinho, publicada em 1979, pela Editora Nova Fronteira. Interrogo esse documento com as seguintes questões: como Magdalena foi direcionada e motivada a estudar na França? Como as experiências artísticas e pedagógicas nas viagens a Paris marcaram a vida da artista? Após seu retorno ao Brasil, quais foram os desdobramentos do seu saber musical e docente no país?

\footnotetext{
${ }^{1}$ Relato de Magda Tagliaferro no Programa Jogo da Verdade. São Paulo: TV Cultura, 1986 disponível no documentário $O$ mundo dentro de um piano (2004).
} 
O livro autobiográfico da artista foi originalmente escrito em francês, idioma que a instrumentista dominava desde sua infância. Apesar de ter nascido no estado do Rio de Janeiro, na Cidade Imperial de Petrópolis, em 19 de janeiro de 1893, e morrido na cidade do Rio de Janeiro, capital do estado, em nove de setembro de 1986, seus pais não eram brasileiros. O Casal Tagliaferro era originário da França e, no seio da família, na maior parte do tempo, falavam a língua materna.

A utilização da língua românica na intimidade familiar, como também nas viagens a Paris, faz-me pensar que escrever as memórias em francês foi uma estratégia de Magdalena para retomar suas memórias pedagógicas e musicais, já que, muitas das vezes, as lembranças do ser humano estão vinculadas à afetividade, aos pontos de referências que existem fora dele. Como no caso da infância da pianista muitas vivências familiares foram em francês, acredito que escrever na língua utilizada no lar dos Tagliaferro era uma maneira da concertista fomentar a memória e trazer à tona as cenas, os sons do seu passado, os episódios, as aulas de outrora que constituíram o seu imaginário.

Ainda sobre este aspecto, a escolha da pianista pelo francês nas escritas autobiográficas parece-me, por um lado, demonstrar que pensava em guardar suas memórias para o público da França, por outro lado, pode-se depreender também que pretendia apresentar aos brasileiros a sua erudição e o seu trânsito fluente na cultura francesa. Isso porque, como destacou Artières, "o arquivamento do eu é uma prática de construção de si mesmo" (ARTIÈRES, 1998, p. 11), para a própria pessoa e para o outro. Assim, no momento em que se pensa nos leitores, nos alunos, no legado dessa escrita, há uma seleção de dados e informações que são arranjados e podem ser harmonizados com uma intenção explícita ou inconsciente. Como explica Bourdieu (2006), o registro (auto)biográfico é um palco onde acontece a encenação de papéis sociais multifacetados, por onde transitam em diferentes temporalidades, as quais o autor ao escrever precisa arrumar e organizar para tornar a sua narrativa coerente.

No caso das memórias de Madalena, a seleção e a autocensura são escritas logo no título do livro, com as palavras que anunciam as restrições - "Quase tudo...”. Chamada que torna o texto instigante e provoca certa erótica em torno das viagens, práticas decorrentes da carreira de Tagliaferro como pianista e professora, uma vez que suas 
turnês musicais e pedagógicas eram bastante conhecidas pela comunidade que acompanhava a música de concerto no Brasil e na França.

Logo nas primeiras páginas do livro, há também expressões que de algum modo insinuam a mesma intencionalidade. A pianista dedicou o livro aos seus amantes "de longe ou de perto" (TAGLIAFERRO, 1979, p. 6). Além disso, nos primeiros parágrafos do corpo do livro, a artista demonstra consciência dos arranjos necessários para a publicação de sua autobiografia em forma de livro ao escrever:

Por que não comecei, há mais tempo, a pôr em ordem estas lembranças? Pudor, sem dúvida. Nada me parece mais delicado do que condensar sobre uma folha de papel o que trazemos oculto na mente e guardado bem fundo no coração, abrigo secreto de olhares alheios. Quando penso em contar tudo, toda a verdade, será que poderia fazer sem risco de magoar - quem sabe - até mesmo a um desconhecido? (TAGLIAFERRO, 1979, p. 7)

Ao mesmo tempo, Magdalena Tagliaferro, com essas palavras, demonstra em alguma medida pudor, fomenta a curiosidade dos seus leitores, seus alunos e torna o texto sedutor. Pois, conforme o pensamento de Araújo, a escrita que prende a atenção dos olhos de muitos é um mapa que confunde o próprio território, perto das confissões da vida íntima, "sob o viés do erotismo que se entreabre" (ARAÚJO, 2012, p. 1). Sendo assim, de maneira bastante atraente, da margem europeia do Atlântico, os rastros das histórias relacionadas ao ensino da música surgem nas linhas que contam as proximidades da brasileira com o seu principal orientador do Conservatório de Paris, o professor Alfred Cortot, um dos interpretes mais conhecido do século XX, principalmente pela qualidade da performance de peças do período romântico e do estilo impressionista.

Por um lado, o da margem americana do Atlântico, as viagens de Magdalena são um tema relevante no campo da História da Educação. Isso, na medida em que pode trazer à baila como o impressionismo na música foi divulgado entre os pianistas brasileiros. Por outro lado, o da margem europeia do Oceano, o estudo é importante por iluminar a trajetória da artista no Conservatório Nacional de Paris, berço da música impressionista. Em outras palavras, este estudo é importante por ressaltar as estratégias 
utilizadas pela pianista para transmitir os conhecimentos musicais europeus aos intérpretes brasileiros, com as obras dos compositores Ravel, Fauré, Debusy, Cortot, por meio das aulas públicas.

Reafirmo a importância destas reflexões sobre as viagens da pianista pelo fato de realçar a própria trajetória de Magdalena Tagliaferro. Esta docente brasileira teve projeção internacional e atuou como catedrática numa das instituições mais importante de música do mundo, o Conservatório de Paris. Uma artista que tocou nos principais palcos musicais conhecidos do seu tempo, que foi júri dos mais renomados concursos de piano. Hoje, geralmente conhecida apenas por um pequeno grupo em seu país, formado pelos músicos profissionais que trabalham com repertório pianístico de concerto, que utilizam suas gravações como referência interpretativa e por aqueles que ainda vivos, no século passado, acompanhavam o cenário musical do Brasil e da França.

Atualmente, boa parcela do povo brasileiro não conhece a trajetória da educadora e intérprete. No entanto, seu nome é presente nos mais importantes catálogos e enciclopédias de música do mundo. O Grove, talvez a mais importante enciclopédia internacional de música, apresenta Magdalena Tagliaferro como uma "intérprete carismática e chefe de uma verdadeira escola pianística" (DICIONÁRIO GROVE, 1994, p. 925). Por sua atuação como catedrática de piano no Conservatório de Paris e "no Brasil, sobretudo durante a II Guerra Mundial, com seus cursos de interpretação que marcaram época" (idem).

Depois de um rastreamento no banco de teses da CAPES, nos catálogos das principais revistas científicas e anais de congressos científicos do campo da Música e da História da Educação, acredito que este seja o primeiro trabalho que aborda especificamente as viagens de Magdalena Maria Yvonne Tagliaferro. Contudo, vale destacar a tese de doutorado "Magdalena Tagliaferro, testemunha de seu tempo", escrita por Édson Roberto Leite, defendida no programa de Ciências da Comunicação da Universidade de São Paulo em 1999. O estudo foi publicado como livro "Tagliaferro: testemunha de seu tempo" pela Annablume Editora, em 2001, com recursos da FAFESP, e focaliza a trajetória da pianista não só como um instrumento midiático dos compositores nacionais e internacionais, mas também como um agente cultural. 
Aqui, juntamente com as ideias de Alexandra Lima da Silva, com seu estudo sobre as viagens de Rocha Pombo como uma estratégia de legitimação no campo intelectual, penso os períodos de Magdalena na Europa como uma busca pela consolidação da sua carreira como intérprete, como professora de piano e como uma intelectual capaz de mobilizar os fundamentos filosóficos da música, principalmente no campo da estética referente ao impressionismo. Ainda com Silva (2012, p. 25), entendo "que a viagem pode ser definida como memória, [...] uma evocação do passado representado, como um objeto, uma situação, ou mesmo, um instante" dos sonhos da jovem em estudar no exterior, das experiências musicais e afetivas vivenciadas nos pianos, salas e corredores do Conservatório de Paris e das “excursões artísticas que só a morte veio interromper” (DICIONÁRIO GROVE, 1994, p. 925).

Com os conceitos do livro "Viagens Pedagógicas", organizado por Mignot e Gondra (2007), Magdalena é analisada como uma professora viajante, uma descobridora de mundos e de espaços que possibilitam intercâmbios e articulação entre modelos pedagógicos internacionais. Sendo assim, uma reflexão sobre as viagens da pianista Tagliaferro, que envolve o ensino e a aprendizagem da Música, pode significar uma análise científica no campo da História da Educação. Isso, mais especificamente na perspectiva da história da circulação das ideias, com a incorporação e difusão de saberes.

Para dar contornos, na perspectiva metodológica, o texto está organizado em três momentos da trajetória de Tagliaferro, todos para dar sentido à circularidade do saber. No primeiro, preocupo-me em descrever como Magdalena foi despertada por sua família, principalmente por seu pai - o cantor Paulo Tagliaferro, que estudou na cidade parisiense e que Ihe ensinou as primeiras lições musicais - para ir estudar na França. Depois, no segundo momento, centro as atenções na trajetória da musicista no Conservatório de Paris, na relação profissional e afetiva com o músico Alfred Cortot e nas questões de gênero que envolviam as viagens de uma mulher naquele período. Por último tópico, mas não menos importante, seguem as análises do convite do Ministro da República, Gustavo Capanema, à concertista para realizar um trabalho musical-pedagógico no Brasil, os conteúdos das aulas e a abordagem didática da professora nos cursos públicos de interpretação pianística, momento no qual perpassava os saberes adquiridos nas viagens. 


\section{Preludiando as viagens: "esta menina precisa ver e ouvir outras coisas"}

A primeira viagem de Magdalena à França foi realizada num tempo em que a pianista ainda desfrutava da ingenuidade infantil, como pode ser percebido nas suas considerações sobre quando cruzou o Atlântico para conhecer os avós alsacianos que viviam no velho mundo. Sobre esta experiência com os pais de sua mãe, escreveu: "Moravam perto de Paris, numa casa com jardins. Ainda me lembro das deliciosas tortas de ameixas colhidas do pomar, que minha avó Rosine fazia, obedecendo a mais autêntica tradição alsaciana. Era um casal de velhos adoráveis" (TAGLIAFERRO, 1979, p. 12). Sobre a avó paterna, que também visitou na Europa, fez seguintes referências: "A mãe de meu pai também morava em casa com quintal, mas na Normandia. Lá, o que havia em quantidade eram maçãs, peras e uvas, também colhidas, orvalhadas, ao amanhecer. Que orgia de frutas na minha primeira infância" (TAGLIAFERRO, 1979, p. 12).

Dessa maneira, Magdalena demonstra serem as memórias da primeira viagem vinculada aos sabores, chega a denominar esse momento da vida como primeira infância e não faz referência direta à música, destaca: "um tempo risonha e séria, gulosa, certamente, mas deixando-se tentar em especial por tudo quanto era poético" (TAGLIAFERRO, 1979, p. 12). A pianista realça a ingenuidade desse período como diferencial das demais viagens. Sendo assim, se pensarmos de forma inversa, se essa foi ingênua, nas entrelinhas, ela indica que as seguintes excursões não foram realizadas com a mesma inocência.

Dois meses depois de voltar para sua pátria, mudou-se de Petrópolis - cidade serrana do estado do Rio de Janeiro - para morar na capital paulistana. Neste período, juntamente com Paulo Tagliaferro, fez uma série de viagens pelo interior do estado de São Paulo. Estas rotas entre os municípios paulistas foram realizadas com objetivo de acompanhar o violoncelista Pablo Casals e o pianista inglês Harold Bauer, amigos do pai de Magdalena, da época que cantava na França. O duo instrumental fez uma série de apresentações pelo Brasil. Sobre acompanhar a turnê desses renomados músicos viajantes, Magdalena registrou nas memórias um ensinamento bastante significativo para a carreira de um instrumentista. No seu livro autobiográfico, o mencionou como segue: “Recebi então a minha primeira grande lição do que significa a laboriosa vida de um 
artista digno de nome. Mesmo tendo dado um recital na véspera, tanto um como outro estudavam diariamente e, ainda que fosse um programa repetido, ensaiavam juntos" (TAGLIAFERRO, 1979, p. 16). O legado dessa viagem pelas cidades do estado brasileiro foi além dessa lição, nas palavras de Tagliaferro:

Ele apegou-se de maneira curiosa à pequena pianista e insistiu muito com meu pai para que me levasse a estudar em Paris, apesar de me considerar esplendidamente orientada. E acrescentava com o seu acento catalão, muito pronunciado naquela época: "Esta menina precisa ver e ouvir outras coisas". Eu, que não sonhava a não ser com novidades, dei pulos de alegria com a ideia. E não tinha dúvidas de que isso acabaria por acontecer. O que não suspeitava, ai de mim, é que por motivos muito mais graves. (TAGLIAFERRO,1979, p. 17)

Como indicam as palavras de Magdalena, o sonho de viajar para estudar começou quando o violoncelista Pablo Casals aconselhou o seu pai, o cantor Paulo Tagliaferro, a transferir-se com a menina para Europa e inscrevê-la nos exames de ingresso no Conservatório de Paris. Porém, esse desejo da pianista demorou a acontecer; a adolescente foi estudar em regime semi-interno no Colégio Sion de São Paulo, um educandário da Congregação de Nossa Senhora de Sion, irmandade fundada na França, no século XIX. Nessa escola, o cenário do sonho passou da Cidade Luz para ser um convento no modelo da congregação francesa, onde a jovem desejava ser a organista e chamada de irmã.

Este sonho sacro de Magdalena não se concretizou; seu pai não permitiu que continuasse seus estudos na instituição confessional paulistana. Então, passou a tomar aulas na residência da própria família Tagliaferro. Para ela se desvincular do apelo religioso dos colégios católicos, pois como sinaliza Vasconcelos, a "casa era o lugar em que as elites educavam os seus filhos e filhas, por meio de professores, mestre ou preceptores" (VASCONCELOS, 2013, p. 1), conforme suas crenças, filosofias e ideologias. Em outras palavras, nesse modelo, muito utilizado no século XIX e no início do XX, "os professores particulares ou mestres particulares eram os que davam lições 'por casas', em dias ou horários pré-estabelecidos" (Idem). Em outras palavras, sob o controle da 
família, as crianças, os adolescentes e os jovens ficavam distanciados das intencionalidades do Estado ou da Igreja.

Contudo, a capital francesa, Paris, não foi o primeiro destino artístico de Magdalena, seja para a apresentação numa cerimônia religiosa, para a performance nos palcos, ou ainda, para aprimoramento da técnica pianística. Suas viagens iniciais com objetivos musicais foram pelos países fronteiriços com o Brasil, uma turnê pela América Latina, para qual estudou muito, preparando-se por longo período. Este foi um dos primeiros planos da família Tagliaferro para a carreira da menina, que era vista pelo público como talentosa, e que atravessou o Atlântico.

A pianista brasileira, em suas memórias em forma de livro, narra o início da sua carreira internacional da seguinte maneira: “Meu pai, que acalentava pretensões bem maiores para mim do que as de simples criança prodígio, ainda me fez trabalhar mais dois anos antes de me lançar numa turnê de concertos pelo sul do Brasil, Argentina e Uruguai” (TAGLIAFERRO, 1979, p.15).

A partir dessa turnê pela Americana do Sul, segundo os relatos autobiográficos, não tardou muito para chegar o momento da viagem à França, na qual iniciou seus estudos em Paris. Quando a pianista estava com treze anos de idade, por um "motivo muito mais grave" que a música, como citado anteriormente, a família seguiu para Europa com pouco planejamento. A família Tagliaferro foi recomendada por um médico brasileiro a cruzar o Oceano para o tratamento da grave enfermidade cardíaca do pai de Magdalena. Nesse período, após sensível melhora do seu progenitor, prestou exame de admissão no Conservatório Nacional de Música de Paris, concurso no qual tocou a Terceira Balada de Frédéric François Chopin. Peça bastante complexa para uma intérprete adolescente, considerando que há nessa música instrumental do compositor polonês uma perspectiva de caráter narrativo, um drama sonoro com mudanças de atmosferas e demandas mecânicas rebuscadas na perspectiva técnica.

Assim, deu-se início à longa série de viagens de Magdalena Tagliaferro, que cruzava o Oceano Atlântico e ligava os conhecimentos pianísticos da França ao Brasil. Um movimento que por meio dos olhos da viajante "coloca em contato dois mundos. É como se o ver [nesse caso conjugado com o ouvir] fosse a origem do saber" (CHAMON, 2007, p. 55). A brasileira experimentava as novas perspectivas no velho mundo, principalmente no 
Conservatório de Paris com as obras de Debussy, nas quais "a música dissolve os contornos da progressão tonal tradicional com os aspectos modais ou cromáticos e transmite estados de espírito e emoções em torno de um tema, em vez de apresentar uma imagem musical detalhada" (DICIONÁRIO GROVE, 1994, p. 450).

Vale destacar que, do final do século XIX em diante, boa parte dos brasileiros que podiam fazer uma viagem à Europa estava mudando sua rota de viagem para os Estados Unidos da América, pois a América do Norte transformara-se em alternativa atraente nos aspectos político e cultural. Para esse grupo financeiramente privilegiado, aquela nação "ter sido colonizada ao mesmo tempo em que o Brasil, de suas instituições serem também recentes, dele ter sido um país escravista até recentemente e, somado a isso tudo, de ser um país também de dimensões continentais, criava proximidades" (CHAMON, 2007, p. 47). Então, para muitos do país colonizado pelos dominadores europeus portugueses, o norte da América era um novo horizonte, principalmente na perspectiva de rompimento com o modelo europeu. Sendo assim, penso que Magdalena não seguia ao encontro do modismo do período. A França já não era o destino mais cobiçado pelos brasileiros naquele momento. Parece que as viagens iniciais da pianista à França se deram de forma bastante natural e, por meio dos laços familiares, chegou ao Conservatório de Paris.

\section{No conservatório de Paris: experiências musicais e afetivas}

Na segunda viagem à Europa, Magdalena Tagliaferro ficou vinculada ao velho mundo, principalmente pelo Conservatório Nacional de Música de Paris, uma das mais renomadas escolas de música do Mundo, que se destaca especialmente por sua vocação na formação de compositores e pianistas. Por suas salas, instrumentos e corredores, passaram músicos de notoriedade internacional artística, e significativa parte da música francesa modernista de concerto foi escrita e interpretada pela primeira vez por seus alunos e professores. Nessa instituição, a concertista teve convívio com exímios músicos, que associados ao seu desejo de aperfeiçoar-se, descrito nas escritas autobiográficas, possibilitaram que incorporasse sofisticadas nuances do impressionismo à sua prática interpretativa. 
Vale destacar que, no renomado Conservatório, a pianista brasileira teve contato com alguns dos mais relevantes mestres do campo musical do seu tempo. Dentre os músicos com quem conviveu na instituição parisiense, destaco neste texto aquele que era a principal referência da musicista: Alfred Cortot, professor que pouco se preocupava com a técnica de Magdalena, por considerar que a sua facilidade digital natural poderia suprir as demandas das músicas. Talvez o experiente professor fizesse isso para evitar embates com a jovem.

Penso assim porque, por um lado, o pianista suíço era alvo das críticas de Magdalena quando escrevia e orientava dedilhados para a execução das peças musicais. A jovem justificava a não aceitação das orientações dele dizendo: “Muitas vezes indicavame dedilhados, perfeitos para suas mãos, que eram grandes, impraticáveis para as minhas, que são pequenas" (TAGLIAFERRO, 1979, p. 27). Por outro lado, a pianista realçou:

[...] maravilhosos, realmente, eram os horizontes que ele me desvendava, as imagens que fazia reluzir diante de meus olhos atônitos, falando-me da natureza, dos sentimentos do coração, da ternura, da paixão, de tudo enfim. [...] No momento em que se sentava ao piano para dar um exemplo, tudo como que se iluminava, e ele nos tornava mais inteligentes. Despertou-me pela descoberta harmônica, pelas vibrações sonoras e um interesse apaixonado pela arte do pedal. (TAGLIAFERRO, 1979, p. 27)

Além dessas questões musicais, Alfred Cortot pensou em outros aspectos da carreira da brasileira. Incentivou-a estudar canto e sugeriu seu nome artístico. Ao orientála nas aulas sobre como deveria preparar os cartazes dos concertos, Cortot percebeu que Magdalena Tagliaferro era um nome bastante comprido para as divulgações publicitárias, por serem os dois nomes juntos demasiadamente extensos. Por isso, o músico suíço sugeriu a jovem que suprimisse algumas letras nas propagandas das apresentações, utilizando o nome artístico: Magda Tagliaferro. Segundo Leite (INSETIR DATA), essa mudança foi marcante pelo fato que a artística ficou mundialmente conhecida como Magda, uma “marca da famosa concertista. Entretanto, no Brasil este nome não logrou 
êxito, permanecendo Magdalena ou Dona Magdalena, como os alunos e admiradores costumavam chamá-la" (TAGLIAFERRO, 1979, p. 27).

A instrumentista escreveu que o músico suíço, no decorrer das aulas no Conservatório de Paris, constantemente sugeria matrículas nas classes de canto, para que ela aperfeiçoasse a técnica vocal e juntos fizessem turnês com diferentes destinos, com um repertório que envolvia músicas italianas, alemãs e francesas. Uma estratégia para que a jovem tivesse contato com as redes de sociabilidade do viajado músico. Em suas escritas menciona que Cortot a "fazia ver como seria maravilhoso" ela ser "cantora e ele [...] acompanhar os belos lieder de Schubert, Schumann e nas canções de Fauré" (TAGLIAFERRO, 1979, p. 33).

Ao seguir as orientações do músico suíço, a pianista chegou a fazer recitais de canto, entretanto, o repertório indicado pelo professor de piano não foi o seu favorito. A jovem ficou encantada mesmo com as óperas de Eugène Wagner. Na França, cantou algumas obras do compositor. Chegou a ser acompanhada pelo músico, com o mestre Alfred Cortot virando as páginas. No Reino da Espanha, participou como cantora da ópera Fausto, do compositor alemão Schumann, o Réquiem Alemão - Op.45 -, de Johannes Brahms. Ambas as obras, consideradas de grande porte, foram apresentadas por completo com coro e orquestra. Apesar de ficar mais próxima de músicos que eram homens importantes do século passado ao utilizar a voz, Magdalena optou por afastar-se do canto.

Pelo que sugere a autobiografia, Magdalena estudava muitas horas de canto por dia, uma rotina comum para os pianistas de alto desempenho, porém uma prática arriscada para aqueles que dedicam à vida há pouco tempo ao canto, sem um preparo técnico e muscular que demanda anos. Os registros dos problemas de rouquidão da concertista parecem-me associados à saturação das pregas vocais. Tagliaferro chega a transparecer compulsividade nos estudos musicais. Atividades que são mais possíveis de serem administradas num instrumento que utiliza partes mais fortes do corpo. Como no seu caso o piano que é tocado com as mãos, os braços, os pés, que são bastante resistentes se comparados com o aparelho fonador. Até mesmo porque a concertista já havia construído progressivamente uma resistência muscular no decorrer de muito tempo que investira no teclado. 
Ao escrever sobre o piano, o canto e os seus mestres no Conservatório de Paris, Magdalena Tagliaferro também relata que o seu principal professor era apaixonado por ela, desde o tempo em que era uma adolescente. A pianista, no decorrer da autobiografia, parece querer comprovar para o leitor que sua relação com o músico suíço era profissional nas viagens e era sempre ele que se declarava para a pianista. Nesta perspectiva, deixou registrado: "Foi no trem que nos levava de volta à Paris que Cortot me fez - quando eu era apenas uma adolescente - uma declaração que me deixou muito atônita. Despertava eu, assim, muito cedo, para o precipitado pulsar do coração" (TAGLIAFERRO, 1979, p. 25).

Porém, logo depois que menciona uma investida do músico, nos parágrafos seguintes, é possível ler que a pianista brasileira refutava qualquer contato sexual com ele nos caminhos percorridos, nas viagens musicais de quando se apresentavam como artistas ou ministravam conferências pedagógicas. Apesar de Magdalena Tagliaferro jamais negar a sua admiração por Cortot como homem, está mencionada na autobiografia uma das justificativas apresentadas para afirmar que jamais teria um caso amoroso com o músico. Ela assim contou:

Tive, no entanto, a coragem de responder que era amiga de sua mulher, a quem acabávamos de deixar, e que me parecia inadmissível falar-me daquela maneira. Considerava uma atitude heroica lutar contra a corrente que me arrastava em direção a alguém que me fascinava. [...] Deu-se por satisfeito por algum tempo. Imagino que o procedimento e a firmeza dessa mulherzinha de cabelos ruivos que chegavam aos joelhos devem ter surpreendido bastante meu mestre. (TAGLIAFERRO, 1979, p. 26)

No período em que ocorreu esse fato, a pianista ainda era uma adolescente que acabara de perder o pai. Um momento no qual, talvez carente, possa ter confundido seus sentimentos na relação estabelecida com o mestre, que tinha 33 anos. Magdalena também vinha do Brasil, de uma cultura diferente da do velho mundo, contexto no qual a França já estava inserida. Na conjuntura brasileira, do final do século XIX e em parte significativa do $\mathrm{XX}$, as mulheres não costumavam viajar, principalmente sozinhas, desacompanhadas do pai ou, quando já com mais idade, do marido. Conforme analisa Mirian Leite (1997), o quantitativo reduzido de viajantes mulheres - quando comparado 
ao número de homens, ainda mais recorrente nas viagens demoradas e com pouca segurança, como é a de travessia do Oceano Atlântico - sinaliza poucos espaços para aquelas que desejavam ou precisavam se deslocar para o continente europeu.

Então, Magdalena chegou à França acompanhada da presença masculina, o cantor Paulo Tagliaferro. Com a morte dele na Europa, meses depois, Cortot parece ter exercido a função de representação da figura masculina que as viagens demandavam. Apesar de se mostrar um personagem à frente de seu tempo, como é comum nas autobiografias (BOURDIEU, 2006, p. 183-191), é interessante perceber que a pianista seguia o modelo de ressaltar a presença do homem, pois pouco menciona até a sua mãe na autobiografia em forma de livro. Não divulga nem mesmo o seu nome. Possivelmente para escrever as páginas iniciais de suas memórias, ao fazer uma releitura de suas memórias, a concertista deixou registrado para a posteridade: "Verifico que só incidentalmente mencionei minha mãe, deixando talvez parecer que ela não significasse muito" (TAGLIAFERRO, 1979, p. 14).

Uma equiparação da sua postura às atividades masculinas aparece no seu texto de maneira bastante frequente. Por exemplo, depois de algum tempo na França, a pianista mostra-se muito articulada com a cultura parisiense e chega a descrever-se como uma mulher mais desenvolta do que muitas nascidas em Paris. Magdalena demostra não querer ser categorizada como uma mulher do seu tempo ao escrever: "veio a era do automóvel: fui uma das primeiras mulheres em Paris que revolveu guiar sozinha. E evidentemente, só gostava de carros, no mínimo, do tipo bólido" (TAGLIAFERRO, 1979, p. 40). Em outras palavras, apresentava-se de "vanguarda" por ser diferente das outras mulheres, por dirigir um carro possante, atividade que na época era quase sempre realizada por homens.

No contexto do Conservatório de Paris, ela não era diferente; não se harmonizava com pessoas do gênero feminino. Por exemplo, dentro e fora da instituição, no meio musical de um modo geral, houve muitos problemas da brasileira com a pianista francesa Marguerite Long. Uma mulher que ganhou prêmios bastante significativos e tinha uma carreira com características bem semelhantes a da trajetória da artista sul-americana. $\mathrm{Na}$ autobiografia não há problemas fortes da Magdalena Tagliaferro com homens. Comenta somente uma leve diferença de ideias com o professor Raoul Pugno, que não tinha uma relação boa relação profissional com Cortot. 
Os principais destaques de Magdalena Tagliaferro em Paris até voltar ao Brasil, na Segunda Guerra Mundial são: em 1907, a conquista da medalha de ouro do Conservatório Nacional Superior de Música de Paris, pelo primeiro lugar no concurso de piano; depois, em 1928, recebeu a condecoração Legião de Honra da França; e, em 1937, quando se tornou catedrática do Conservatório francês, no curso superior de piano, sucedendo a cadeira que era de Isidore Philipp.

Na década de 1930, veio muitas vezes ao Brasil para tocar. Transitou bastante entre o Rio de Janeiro e a cidade de São Paulo, mas manteve residência na capital francesa. No entanto, com a Segunda Guerra Mundial, o Conservatório Nacional Superior de Música de Paris, onde ela estudou, trabalhava e já atuava como catedrática, interrompeu suas atividades e fechou as portas por anos. Então, no final dos anos 30 do século passado, a pianista voltou a morar no Brasil, sua pátria.

Nesta de perspectiva de retorno de Magdalena à América do Sul, ao estabelecer novamente residência no Brasil, questiono: após a formação francesa, quais eram as estratégias da pianista para a manutenção da carreira artística em sua pátria? Como as suas atividades pedagógicas e musicais podem ter contribuído no processo de ensino e aprendizagem do piano? De que maneira selecionou e sistematizou os conteúdos para a formação dos jovens brasileiros estudantes de piano?

\section{Aulas públicas de interpretação pianísticas: novas concepções entre admiração e repulsas}

O brasileiro foi sempre muito musical e traz ritmo dentro de si. Naquela época, acrescentar-lhe cultura musical só lhe podia ser útil.

Magdalena Tagliaferro, ${ }^{2}$

De volta ao Brasil, em 1939, Magdalena Tagliaferro foi convidada pelo Ministério da Educação, na época dirigido por Gustavo Capanema, para pensar, discutir, criar e implantar um curso de formação pianística. Isso porque os políticos, os gestores da

\footnotetext{
${ }^{2}$ Relato de Magda Tagliaferro no Programa Jogo da Verdade. São Paulo: TV Cultura, 1986, disponível no documentário $O$ mundo dentro de um piano (2004).
} 
educação e os intelectuais do Brasil entendiam que os brasileiros que possuíam conhecimentos adquiridos no exterior, nos países entendidos como mais "civilizados", poderiam ser referência para a difusão de novos modelos educativos.

Nesse período, havia um fomento direcionado na efetivação de mudanças na educação brasileira. Como destacam Mignot e Gondra, a circularidade do saber foi recorrente para operar mudanças ao seguirem modelos, "tomando como parâmetro experiências realizadas no estrangeiro. Educadores de um modo geral e reformadores, em especial, lançaram mão de uma série de estratégias para se aproximarem do que havia de mais moderno em termos de educação" (MIGNOT; GONDRA, 2007, p. 8). Fato que acontecia tanto na esfera das práticas docentes quanto na publicação de materiais didáticos, periódicos e relatórios.

Nessa perspectiva de compartilhar conhecimentos, de trazer ao Brasil os novos saberes e fazê-los circular entre os estados da federação, Magdalena planejou um curso com aulas em forma de conferência. Assim, compartilhava as técnicas mais inovadoras que os pianistas franceses utilizavam. As aulas públicas da concertista ficaram bastante conhecidas. O lançamento do projeto foi em São Paulo, depois houve edições em outros estados brasileiros, mas o principal palco utilizado por Tagliaferro estava no Rio de Janeiro, então Distrito Federal, no Salão Leopoldo Miguez, da Escola Nacional de Música (hoje Escola de Música da Universidade Federal do Rio de Janeiro - EM - UFRJ). Sala de concerto inspirada na arquitetura da Sala Gaveau, situada em Paris, espaço bastante frequentado por Tagliaferro na Europa.

As aulas são descritas pela pianista como fascinantes, como mencionou: "em aspectos bem diferentes, uma aula pública me fascina tanto quanto um concerto" (TAGLIAFERRO, 1979, p. 117). Porém, o projeto construído com o Ministro da República, Gustavo Capanema, inicialmente sofreu resistência por parte dos colegas professores de piano da Escola Nacional de Música. Magdalena conta que quando chegou ao foyer do Salão Leopoldo Miguez, onde ministrou mais vezes o curso público de interpretação pianística, o diretor da instituição, Sá Pereira, falou o seguinte: "Sinto-me constrangido de Ihe dar a ler esta carta anônima que acabo de receber. Por mais desagradável que seja, se eu a ocultasse, tanto quanto a conheço: você havia de ficar ressentida" (TAGLIAFERRO, 
1979, p. 80), porque a missiva continha ameaças, como: “Não permitiremos que Magda Tagliaferro faça o seu curso. Nós a impediremos de falar” (TAGLIAFERRO, 1979, p. 80)

A Escola Nacional de Música, originária do Conservatório de Música, fundado nos tempos do império, mantinha-se com um espaço de resistência aos novos movimentos e estilos musicais. Postura que Villa-Lobos também enfrentou quando criou o Curso de Formação de Professores de Música e Canto Orfeônico no Instituto de Educação do Rio de Janeiro (MONTI, 2014), na Superintendência de Educação Musical e Artística do Distrito Federal, que, com o passar dos anos, foram consolidados com a criação do Conservatório Nacional de Canto Orfeônico, em 1942 (MONTI, 2011), ou seja, no mesmo período das aulas públicas de interpretação de Magdalena.

No Curso Público de Interpretação Pianística, a concertista apresentava novos conteúdos e, além disso, sua didática era bastante diferente das utilizadas pelos tradicionais professores da Escola Nacional de Música. Os dados da pesquisa de Leite ratificam este novo modelo implantado no meio musical brasileiro pela concertista, pois afirma que:

\begin{abstract}
Magdalena possuía um carisma que envolvia a todos os ouvintes num processo similar ao que ocorre em nossos dias com atrizes e apresentadores de televisão. A mestra, com sua maneira fácil e espontânea de falar, transmitia ao público mais que os ensinamentos da interpretação pianística. (LEITE, 1997, p. 156)
\end{abstract}

Dessa maneira, além de trazer as técnicas interpretativas do impressionismo francês, ao mesmo tempo, a pianista transmitia ao povo brasileiro um estilo mais leve e humanizado de ensinar piano. Já que, por muitos anos, os professores de música posicionavam-se de maneira bastante autoritária e o ensino do instrumento era feito com bastante inflexibilidade. Isso acontecia porque, geralmente, o professor de música não abria mão de "um corpus de conhecimentos, dos valores da representação da música de um dado momento histórico" (DUARTE; MAZZOTTI, 2006, p. 1283-1295). Como Duarte e Mazzotti constataram, "esses conhecimentos, valores e representação podem ser considerados perenes, afastando, assim, esses professores dos grupos sociais expressos nas atitudes e escolhas de seus alunos" (Idem). 
As aulas públicas de interpretação pianística de Magdalena Tagliaferro foram inspiradas nas Conferências da Université dês Annales. Mais especificamente, na palestra que chamou de UnBouquer d'Auteurs Modernes, que pode ser traduzida para a língua portuguesa como Um Buquê de Compositores Modernos, na qual abordou as obras musicais de Debussy, Reynaldo Hanhn, Jean Rivier, Maurice Ravel, Jacques Ibert e Darius Malhaud. O evento artístico e acadêmico habitualmente acontecia na Sala Gaveau, em Paris.

A brasileira conta que essa palestra na França foi formulada com a ajuda de Alfred Cortot, numa ocasião em que a musicista foi substituí-lo por causa de um conflito de datas. O músico suíço havia planejado uma turnê pelo Brasil e não desmarcara a conferência que estava agendada dentre os dias reservados para o período dessa viagem à América do Sul. Assim, percebe-se que as aulas públicas de Tagliaferro tiveram origem nas ideias do seu mestre, professor do Conservatório parisiense.

Algumas das técnicas trazidas da França por Madalena Tagliaferro e ministradas nos cursos públicos de interpretação pianística são abordadas como "sugestões aos jovens pianistas" (TAGLIAFERRO, 1979, p. 118) na autobiografia. A concertista abordou os conteúdos no livro: exercícios de relaxamento para os braços e ombros; parâmetro para o posicionamento ao piano e altura da banqueta; a forma da mão com a preservação da firmeza e o peso nos dedos; a sinestesia como uma ferramenta para continuidade sonora; a utilização do pedal de maneira estudada com fins estéticos e não como um recurso para disfarçar as dificuldades mecânicas; planejamentos de estudos gradativos de velocidade, partindo de Czerny, Cramer chegando aos de Chopin com a técnica bastante consolidada; e uma programação de estudo diária, que prevê o descanso de trinta minutos para cada duas horas ou duas horas e meia de estudo.

Por um lado, relacionado à formação pianística, as aulas e orientações da artista foram relevantes para a performance dos jovens brasileiros por meio do curso público de interpretação pianística. Além disso, abriu caminhos para muitos instrumentistas que ganharam recursos para estudar em Paris, com bolsa do governo francês. A professora também criou, em São Paulo, a Fundação Magda Tagliaferro, para dar continuidade à sua “escola" no Brasil. Por outro lado, sobre sua relação ao povo mais amplo, ou seja, na perspectiva de formação da plateia, como intérprete, Magdalena dizia ter um 
compromisso com a terra que a viu nascer. Contava ter orgulho por sido o meio para levar ao conhecimento do público do seu país um repertório de música francesa, até então, quase ignorado nos países da América do Sul.

A autobiografia indica que as aulas públicas da Dona Magdalena - modo pelo qual era chamada pelos alunos - deixaram marcas de uma nova maneira de tocar piano no Brasil. Fato que também pude perceber auditivamente nas gravações de Tagliaferro, bem como nos registros sonoros dos seus alunos brasileiros. Ainda destaco que as práticas pedagógicas da professora brasileira não substituem as aulas individuais de piano, mas é inegável que sua estratégia didática, inspirada nas conferências da Université dês Annales, auxiliaram a divulgar de maneira bastante democrática os conhecimentos sobre a música impressionista, oriundos do Conservatório de Paris.

\section{Considerações finais}

Posto isso, considero que analisar "Quase tudo... Memórias de Magdalena Tagliaferro" foi imergir no seu mundo, seguir suas trilhas, viajar pela Cidade Imperial de Petrópolis do final do século XIX, excursionar com seu pai, o cantor Paulo Tagliaferro, pelo interior do Estado de São de Paulo, passar por alguns países da América Latina que fazem fronteira com o Brasil, adentrar num transatlântico e voltar ao Conservatório de Paris no momento de consolidação do Impressionismo, sentar nos pianos dessa escola para repensar as lições e os conselhos do músico Alfred Cortot. Também foi participar das aulas públicas de interpretação pianística da concertista no glamoroso Salão Leopoldo Miguez, da Escola Nacional de Música, na Cidade do Rio de Janeiro, então capital da República.

Nesta viagem, segui os passos da pianista por meio de seus escritos autobiográficos. Percebi que Paris era mais que um destino profissional, pois foi a terra que viu seu pai - aluno do conservatório parisiense, que lhe ensinou ainda menina as primeiras lições de piano - nascer e voltar para morrer. Também porque nessa cidade conheceu o seu mentor artístico e intelectual, pianista internacionalmente renomado, o suíço, Alfred Cortot, músico com quem aprendeu a poética do piano romântico e, 
principalmente, a tocar o repertório dos músicos franceses modernistas. Músicas desvinculadas do sistema de tonalidades maior e menor, das estruturas musicais que haviam ditado os contornos de quase toda a produção dos compositores ocidentais nos séculos anteriores.

Enfim, ao analisar os registros dos conhecimentos adquiridos por Magdalena Tagliaferro nas viagens à Franca, na década de 1930, e dos cursos públicos de interpretação pianística que ministrou no Brasil, na década de 1940, percebo que a concertista deixou um legado em seu país. Isso porque ensinou uma nova maneira de tocar piano, fruto do que aprendeu em Paris. Como também por serem as suas práticas pedagógicas, trazidas da Université dês Annales, inovadoras e de referência democrática, fato que colocou os estudantes, músicos e professores em contato com um novo modelo musical e pedagógico mais dinâmico e abrangente naquele período.

\section{Referências}

ARAÚJO, Rodrigo da Costa. Sutilezas do erotismo em Roland Barthes. In: Verbo 21: Cultura e Literatura, Bahia. 2012. p. 1-10.

ARTIÈRES, Philippe. O arquivamento de eu. Estudos Históricos. v. 11, n. 21, p. 9-34, 1998.

BOURDIEU, Pierre. A ilusão biográfica. In: AMADO, Janaína e FERREIRA, Marieta de Moraes (Orgs.). Usos e abusos da história oral. 8. ed. Rio de Janeiro: Editora FGV, 2006. p. 183-191.

CHAMON, Carla. Simone; FARIA FILHO, Luciano. Mendes. A educação como problema, a América como destino: a viagem de Maria Guilhermina. In: MIGNOT, Ana Chrystina Venancio; GONDRA, José Gonçalves. (Orgs.). Viagens pedagógicas. 1. ed. São Paulo: Cortez, 2007. p. 39-64.

DICIONÁRIO Grove de música: edição concisa. Editado por Stanley Sadie; editoraassistente Alison Latham. Tradução Eduardo Francisco Alves. Rio de Janeiro: Jorge Zahar Ed., 1994.

DUARTE, Mônica de Almeida; MAZZOTTI, Tarso Bonilha. Representações sociais da música: aliadas ou limites do desenvolvimento das práticas pedagógicas em música? Educ. Soc. v. 27, n. 97, p. 1283-1295, 2006. 
LEITE, Miriam Moreira. Livros de viagem: 1803/1900. Rio de Janeiro: Ed. UFRJ, 1997. LEITE, Edson Roberto. Magdalena tagliaferro: testemunha de seu tempo. 1. ed. São Paulo: Annablume / FAPESP, 2001. v. 1. p. 234.

MIGNOT, Ana Chrystina Venancio ; GONDRA, José Gonçalves. (Orgs.). Viagens pedagógicas. 1. ed. São Paulo: Cortez, 2007. v. 01. p. 320.

MIGNOT, Ana Chrystina Venancio; GONDRA, José Gonçalves. Viagens de educadores e circulação de modelos pedagógicos. In: MIGNOT, Ana Chrystina Venancio.; GONDRA, José Gonçalves. (Org.). Viagens Pedagógicas. 1ed.São Paulo: Cortez, 2007, v. 1, p. 7-14.

MONTI, Ednardo Monteiro Gonzaga. Biografia villalobiana: educação e política entre fendas. In: SILVA, Alexandra Lima da; MONTI, Ednardo Monteiro Gonzaga. (Orgs.).

Escritas (auto)biográficas e histórias da educação. 1. ed. Curitiba: CRV, 2014, p. 107-124.

MONTI, Ednardo Monteiro Gonzaga. A formação docente no Conservatório Nacional de Canto Orfeônico. In: SEMANA DA EDUCAÇÃO - UERJ: OS SENTIDOS DA PEDAGOGIA HOJE, XVI, Rio de Janeiro, 2011. Anais. Rio de Janeiro. Rio de Janeiro: EdUERJ, 2011.

TAGLIAFERRO, Magdalena Maria Yvonne. Quase tudo... Memórias de Magdalena Tagliaferro. Trad. Maria Lúcia Pinho. Rio de Janeiro: Nova Fronteira, 1979.

VASCONCELOS, Maria Celi Chaves. Educação doméstica e escolaridade formal no Rio de Janeiro Oitocentista. In: CONGRESSO BRASILEIRO DE HISTÓRIA DA EDUCAÇÃO, VII, Cuiabá - MT, 2012. Cuiabá - MT: UFMT/FAPEMAT/SBHE, 2013. v. 1. p. 1-15. Tema do evento: Circuitos e fronteiras da história da educação no Brasil

Recebido em: 20/03/2015 Aprovado em: 11/07/2015

Universidade do Estado de Santa Catarina - UDESC Programa de Pós-Graduação em Educação - PPGE Revista Linhas

Volume 16 - Número 32 - Ano 2015 revistalinhas@gmail.com 